\title{
Investigation of the Role of Serum Matrix Gla-Protein as a Biomarker of Calcific Aortic Valve Disease
}

\author{
Amal Al Nawasreh ${ }^{1, *}$, Hussam Shebli ${ }^{2}$ and Sahar Fahoum ${ }^{1}$ \\ ${ }^{1}$ Department of Biochemistry and Microbiology, Faculty of Pharmacy, Damascus University, Damascus, Syria \\ ${ }^{2}$ Department of Internal Medicine, Cardiovascular Disease Section, Faculty of Medicine, Damascus \\ University, Damascus, Syria
}

\begin{abstract}
Background: Calcific aortic valve disease (CAVD) is a major contributor to cardiovascular morbidity and mortality. Circulating total uncarboxylated Matrix y-carboxyglutamate (Gla) protein (t-ucMGP) is a promising biomarker for rapid screening of subjects prone to cardiovascular calcification who may need more invasive vascular diagnostics. Preliminary data show that low t-ucMGP levels are indicative for prevalent vascular calcification. Hence, the aim of our study was to investigate the possible role of circulating t-ucMGP as a biomarker may help in identification patients with CAVD, taking into consideration that CAVD is a form of vascular calcification.
\end{abstract}

Methods \& Materials: We analyzed serum t-ucMGP levels by enzyme-linked immunosorbent assay (ELISA) in 50 patients with echocardiographically proven CAVD and 21 control subjects.

Results: Serum t-ucMGP levels were significantly lower in patients with CAVD $(29.29 \pm 12.18 \mathrm{nmol} / \mathrm{l})$ compared to the control group (36.84 $\pm 21.79 \mathrm{nmol} / \mathrm{l}, \mathrm{p}=0.003)$.

Conclusion: Serum t-ucMGP may help as a noninvasive biomarker for identification of these patients.

Keywords: Calcific aortic valve disease (CAVD), serum biomarker, screening, ELISA, uncarboxylated matrix Glaprotein (UcMGP).

\section{INTRODUCTION}

Calcific aortic valve disease (CAVD) is a chronic disorder characterized by fibrosis and mineralization of the aortic valve [1]. It is divided, on a functional basis, into aortic valve sclerosis (AVSc) and aortic valve stenosis (AVS) [2]. Aortic valve sclerosis (AVSc) is the early asymptomatic phase of CAVD, characterized by a progressive thickening of the valve without obstruction of the left ventricular outflow; whereas aortic valve stenosis (AVS) is the severe symptomatic stage of CAVD, characterized by severe calcification and serious impairment of leaflet motion with subsequent limitation of blood flow through the valve [3,4]. CAVD is the most common heart valve disorder [5]. The prevalence of CAVD increases with age: aortic valve sclerosis (AVSc) is present in approximately $30 \%$ of all individuals over age 65 , however, even in middle age, approximately $10 \%$ exhibit AVSc by echocardiography; whereas aortic valve stenosis (AVS) is present in $2 \%$ to $5 \%$ of very elderly patients $[2,4,6]$. For decades, CAVD was thought to be a passive process in which the valve degenerates with age in association with calcium accumulation in the cusps. Instead, CAVD appears to be an active cellular process that develops within the

*Address correspondence to this author at the Department of Biochemistry and Microbiology, Faculty of Pharmacy, Damascus University, Damascus, Syria; Tel: 00963956527130; E-mail: Amallssam700@Gmail.com valve leaflet with lipoprotein deposition, chronic inflammation, and active leaflet calcification [4,7]. Mechanical stress on the aortic valve in addition to other atherosclerotic risk factors, leads to valvular endothelial dysfunction/ leakage, followed by deposition of lipids, in particular, low-density lipoprotein (LDL) and lipoprotein[a] and other compounds that trigger inflammation, which in turn activates valvular interstitial cells (VICs), the main cellular component of the aortic valve, resulting in their osteoblastic transformation $[1,8,9]$. On the other hand, transformation of valve interstitial cells into osteoblastlike cells is determined by several signaling pathways having reciprocal cross-talks, especially bone morphogenetic protein (BMP) signaling $[1,10]$. BMP-2 expression is activated in the valvular endothelium in response to atherogenic factors found in valve lesions [11]. Activation of BMP2 stimulates 2 osteogenic signaling pathways: the Runx2/Cbfa1 and the $W n t / L r p 5 / \beta$-catenin pathways that promote osteoblastogenesis and the formation of extraosseous calcification $[10,12]$. Currently, the major methods to diagnose CAVD are clinical examination and echocardiography [4]. Hence, it is important to find biomarkers that might be suitable for deriving clinically useful information about the presence, severity, progression and prognosis of CAVD.

() 2019 SET Publisher 
Matrix Gla-protein (MGP) is a $10 \mathrm{kd}$ protein composed of 84 amino acids that belongs to the family of vitamin K-dependent proteins (VKDPs), also known as Gla ( $\mathrm{Y}$-carboxyglutamate) proteins whose activity is strictly dependent on the presence of these Gla residues at a number of well-defined positions [13-15]. MGP was originally isolated from bone, but it is mainly secreted by chondrocytes and vascular smooth muscle cells in the arterial media $[16,17]$. MGP acts as a potent local inhibitor of vascular calcifications by directly inhibiting calcium precipitation and crystallization and by binding to bone morphogenetic protein (BMP2) and antagonizing it (which itself regulates osteoblast differentiation, and thus bone formation), thereby blocking the osteo-inductive effects of it in the vessel wall [17-19]. For both mechanisms of action, MGP has to be carboxylated [20]. It contains 5 Gla residues (formed by post-translational $\mathrm{y}$-glutamyl carboxylation of glutamic acid by vitamin K-dependent carboxylase) in positions 2, 37, 41, 47 and 52. Hence, MGP requires vitamin $\mathrm{K}$ to be activated. Besides carboxylation, MGP also undergoes posttranslational serine phosphorylation (on three serine residues in positions 3,6 , and 9) during maturation. Phosphorylation seems to be important for the cellular secretion of MGP $[19,21]$. Remarkably in the healthy population both carboxylation and phosphorylation are not exerted completely, so that different MGP conformations can be found: phosphorylated (pMGP), non-phosphorylated (desphospho, dpMGP), carboxylated (cMGP) or uncarboxylated (UcMGP). Hence, in the circulation different MGP species may be detected including $p$ cMGP, p-ucMGP, dp-cMGP, and dp-ucMGP $[18,21]$. The circulating levels and isoforms of MGP reaching the circulation depend on the rate of local MGP synthesis in vascular tissue, MGP activity in tissues, its secretion from VSMCs and the subsequent binding of MGP to calcified areas that may be present within the arterial wall $[14,19]$. In the present study, we will focus on total uncarboxylated MGP (t-ucMGP). The accumulation of MGP in its uncarboxylated form (ucMGP) around calcified areas in vasculature (suggesting that UcMGP is not set free into the circulation from calcified arteries, and thus lower serum ucMGP levels in patients with vascular calcification) prompted the development of an ELISA for measuring ucMGP levels. Indeed, using this assay it was found that the serum t-ucMGP levels in patients with vascular calcification are lower than those in a healthy reference population. It was demonstrated that the assay measuring circulating t-ucMGP identified a wide range of patient populations prone to develop arterial calcification. Additionally, preliminary data show that circulating t-ucMGP could have potential to serve as a noninvasive biomarker for cardiovascular calcification and possibly contribute to rapid screening of subjects who may be in need of more invasive vascular diagnostics [22]. Therefore, Our study aimed to investigate the possible role of circulating t-ucMGP as a biomarker may help in identification patients with calcific aortic valve disease, taking into consideration that CAVD is a form of vascular calcification.

\section{MATERIALS AND METHODS}

\section{Subjects}

From March 2016 to April 2017, a cross-sectional study in a total of 50 patients with echocardiographically proven calcific aortic valve disease $(27(54 \%)$ men, mean age $61.3 \pm 10.1$ years, range: $39-80$ years) recruited from the inpatient cardiology department of Al Assad University Hospital and Al Mouwasat University Hospital Damascus was conducted. Included patients had to have a confirmed diagnosis of CAVD on the basis of findings on Doppler echocardiography. Both patients with aortic sclerosis as well as patients with mild, moderate or severe aortic valve stenosis were included. The exclusion criteria were increased serum calcium (calcium> $2.6 \mathrm{mM}$ ) or end-stage renal disease (glomerular filtration rate $(G F R)<15 \mathrm{ml} / \mathrm{min}$ according to the MDRD formula). In addition, twenty-one apparently healthy subjects [16 [76.2\%] men, mean age $45.6 \pm 14.5$ years, range: 25 75 years] were included to serve as a reference group. The study was approved by the local medical ethics committee, and informed consent was obtained from all participants.

\section{t-ucMGP Measurement}

Blood was collected from all participants by venipuncture $(5 \mathrm{ml})$ in serum tubes and stored for 20 min at room temperature before centrifugation (20 min $\times \mathrm{g}$ ). Serum was sub-sampled in $250 \mu \mathrm{l}$ aliquots and frozen at $-80{ }^{\circ} \mathrm{C}$ until testing. Serum t-ucMGP concentrations were quantified with Human (ucMGP) ELISA Kit manufactured by SunRed company, China.

\section{Statistical Analysis}

Data were expressed as the mean $\pm S D$, range, or percentage, as appropriate. Since t-ucMGP concentrations were normally distributed, parametric testing was used. Independent Samples T Test was used to test for differences between groups. Pearson's correlation analysis was used to determine the 
correlation with age. A $P$ value $\leq 0.05$ was considered to be statistically significant. Data processing and statistical analysis was performed using SPSS software, version13.0 for Windows.

\section{RESULTS}

The demographic characteristics of both the study group and control group are shown in Table 1. Serum tucMGP levels were significantly lower in the study group $(29.29 \pm 12.18 \mathrm{nmol} / \mathrm{l})$ than in the reference group $(36.84 \pm 21.79 \mathrm{nmol} / \mathrm{l}, \mathrm{p}=0.003$; Figure 1$)$. With respect to age, as a relevant factor possibly influencing $t-$ ucMGP levels, there was no significant correlation between circulating t-ucMGP and age in both the study group and the control group $(r=0.078, p=0.592 ; r=$ $0.205, p=0.373$, respectively). Additionally, there was no difference between men and women in both groups, as gender is another relevant factor, $(p=0.511 ; p=$ 0.541 , respectively) (Table 2).

Table 1: The Demographic Characteristics of both the Study Group and Control Group

\begin{tabular}{|c|c|c|}
\hline & $\begin{array}{c}\text { Study group } \\
{[\mathbf{n}=\mathbf{5 0}]}\end{array}$ & $\begin{array}{c}\text { Control group } \\
{[\mathbf{n}=\mathbf{2 1}]}\end{array}$ \\
\hline \hline Age [years] & $61.3 \pm 10.1$ & $45.6 \pm 14.5$ \\
\hline $\begin{array}{c}\text { Gender } \\
\text { male/female }\end{array}$ & $27 / 23$ & $16 / 5$ \\
\hline
\end{tabular}

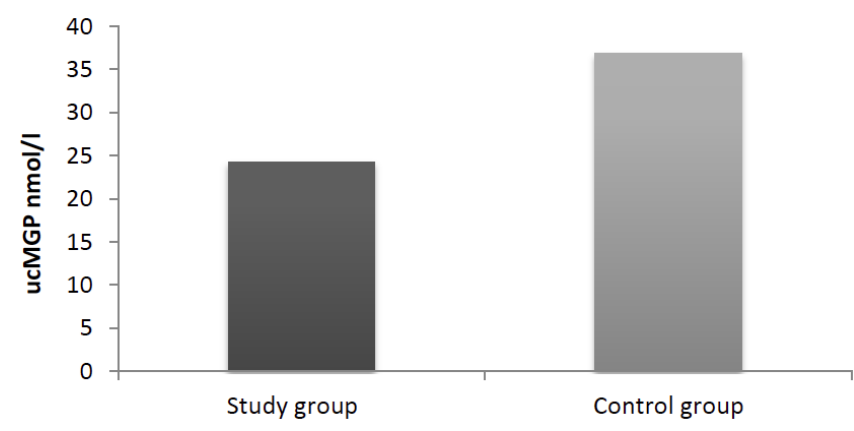

Figure 1: Bar graph demonstrating serum ucMGP levels in patients with CAVD $(n=50)$ as well as in the reference population $(n=21)$.

Table 2: Serum ucMGP Levels in both the Study Group and Control Group with Respect to Gender

\begin{tabular}{|c|c|c|c|}
\hline \multirow{2}{*}{ Study group } & \multicolumn{2}{|c|}{ ucMGP nmol/l } & \multirow{2}{*}{ P-value } \\
\cline { 2 - 3 } & Male & Female & \multirow{2}{*}{0.511} \\
\cline { 2 - 3 } & $25.35 \pm 12.89$ & $23.04 \pm 11.45$ & \\
\hline \multirow{2}{*}{ Control group } & Male & Female & \multirow{2}{*}{0.541} \\
\cline { 2 - 3 } & $38.53 \pm 22.51$ & $31.46 \pm 20.67$ & \\
\hline
\end{tabular}

\section{DISCUSSION}

This study is the first to be conducted in Syria on the role of serum ucMGP as a biomarker of CAVD. In the present study, we show that patients with calcific aortic valve disease have significantly lower levels of circulating ucMGP than apparently healthy subjects. Although the control subjects were younger, the impact of age on ucMGP levels was neglectable, as was shown previously [22]. Moreover, there was no significant correlation between circulating ucMGP and age in both the study group and the reference group. Also there was no difference between men and women in both groups.

The low ucMGP levels in CAVD patients could be explained by the accumulation of UcMGP at sites of arterial calcification- through its negatively charged phosphoserine residues- and consequently less ucMGP setting free into circulation [19]. Indeed, it has been demonstrated that MGP accumulates at areas of calcification in its uncarboxylated form (ucMGP) using immunohistochemical techniques [23]. As total ucMGP includes phosphorylated and non-phosphorylated fractions and given the fact that the observed plasma levels are $>1000$-fold higher than those of dp-ucMGP, t-ucMGP mainly consists of phosphorylated ucMGP species. Since phosphorylation alone is sufficient for the binding of MGP to vascular calcifications via negatively charged phosphoserine residues, the low ucMGP levels CAVD patients are the result of consumption of MGP in the vascular wall with a diminished secretion in the circulation $[19,24]$. However, it is unclear why ucMGP fails to arrest the growth of mineral despite its ability to bind to hydroxyapatite in its uncarboxylated form [25]. Alternative explanation for the low ucMGP levels in CAVD patients may be lower synthesis of MGP. Venardos et al. showed that AVICs in these patients express significantly lower levels of MGP relative to normal AVICs from mRNA to the fully formed secreted protein. Hence, a critical anti-calcification protein, MGP, may be deficient in patients with calcific aortic valve disease [26].

These results are consistent with studies showing lower t-ucMGP concentrations in CAVD patients compared to a healthy reference group $[22,27,28]$. Additionally, our findings are in line with results of studies reporting no significant effect of age and sex on ucMGP levels [27,28].

There are several limitations of this study. First, it is a cross-sectional analysis. A cause-and-effect 
relationship could therefore not be investigated. However, it does allow for assessment of ucMGP as a biomarker for CAVD. Second, the sample size is relatively small, further studies with larger number of subjects will be required to prove the role of ucMGP as a biomarker to identify CAVD patients. Third, the reference group should be demonstrated to be free from cardiovascular calcification; this would require multislice computed tomography (MSCT) or electronbeam computed tomography (EBCT) screening of all healthy volunteers. Since these imaging techniques are expensive, and also because they expose subjects to significant $\mathrm{X}$-ray radiation, we have not characterized our reference group by MSCT or EBCT. We therefore choose for a younger control group since a previous study showed that age did not influence MGP level. However, this may be why our results showed that ucMGP levels in the aortic aortic sclerosis patients, who were 11 patients in our study, were lower than the control group, but the difference was not statistically significant [data not shown].

In conclusion and in support of the previous studies, our results in Syrian population suggest that CAVD patients have significantly lower levels of circulating ucMGP and could be discriminated from the healthy reference population. Hence, ucMGP could be served as a noninvasive biochemical marker for identification of these patients. Further research is needed to evaluate if ucMGP serum levels may become a suitable biomarker for the progression of aortic valve calcification.

\section{CONTRIBUTIONS}

Conception and design: All authors. Collection of study subjects, assembly of data, analysis of samples, data analysis and interpretation, manuscript writing: Amal Al Nawasreh. Supervision, manuscript revision for important intellectual content and final approval of manuscript: Sahar Fahoum.

\section{CONFLICT OF INTEREST DECLARATION}

None of the authors had a conflict of interest to declare.

\section{ACKNOWLEDGEMENTS}

This work was supported by Damascus University.

\section{REFERENCES}

[1] Mathieu P, Boulanger M-C, Bouchareb R. Molecular biology of calcific aortic valve disease: Towards new pharmacological therapies. Expert Rev Cardiovasc Ther 2014; 12(7): 851-62.

https://doi.org/10.1586/14779072.2014.923756

[2] O'Brien KD. Pathogenesis of calcific aortic valve disease: A disease process comes of age (and a good deal more). Arterioscler Thromb Vasc Biol 2006; 26(8): 1721-8. https://doi.org/10.1161/01.ATV.0000227513.13697.ac

[3] Sainger R, Grau JB, Branchetti E, Poggio P, Lai E, Koka E, et al. Comparison of transesophageal echocardiographic analysis and circulating biomarker expression profile in calcific aortic valve disease. J Heart Valve Dis 2013; 22(2): 156-65.

[4] Beckmann E, Grau JB, Sainger R, Poggio P, Ferrari G. Insights into the use of biomarkers in calcific aortic valve disease. J Heart Valve Dis 2010; 19(4): 441-52.

[5] Mathieu P, Boulanger M-C. Basic mechanisms of calcific aortic valve disease. Can J Cardiol 2014; 30(9): 982-93. https://doi.org/10.1016/j.cjca.2014.03.029

[6] Towler DA. Molecular and cellular aspects of calcific aortic valve disease. Circ Res 2013; 113(2): 198-208. https://doi.org/10.1161/CIRCRESAHA.113.300155

[7] Freeman RV, Otto CM. Spectrum of calcific aortic valve disease: Pathogenesis, disease progression, and treatment Strategies. Circulation. 2005; 111(24): 3316-26. https://doi.org/10.1161/CIRCULATIONAHA.104.486738

[8] Zeng $Y$, Sun $R$, Li $X$, Liu $M$, Chen $S$, Zhang $P$. Pathophysiology of valvular heart disease (Review). Exp Ther Med 2016; 11(4): 1184-8. https://doi.org/10.3892/etm.2016.3048

[9] Dweck MR, Boon NA, Newby DE. Calcific aortic stenosis: A disease of the valve and the myocardium. J Am Coll Cardiol 2012; 60(19): 1854-63.

https://doi.org/10.1016/j.jacc.2012.02.093

[10] Leopold JA. Cellular mechanisms of aortic valve calcification. Circ Cardiovasc Interv 2012; 5(4): 605-14.

https://doi.org/10.1161/CIRCINTERVENTIONS.112.971028

[11] Bostrom KI, Rajamannan NM, Towler DA. The regulation of valvular and vascular sclerosis by osteogenic morphogens. Circ Res 2011; 109(5): 564-77. https://doi.org/10.1161/CIRCRESAHA.110.234278

[12] Bossé $Y$, Mathieu $P$, Pibarot P. Genomics: The next step to elucidate the etiology of calcific aortic valve stenosis. J Am Coll Cardiol 2008; 51(14): 1327-36. https://doi.org/10.1016/j.jacc.2007.12.031

[13] Fusaro M, Crepaldi G, Maggi S, Galli F, D'Angelo A, Calò L, et al. Vitamin $\mathrm{K}$, bone fractures, and vascular calcifications in chronic kidney disease: An important but poorly studied relationship. J Endocrinol Invest 2011; 34(4): 317-23. https://doi.org/10.1007/BF03347093

[14] Schurgers LJ, Uitto J, Reutelingsperger CP. Vitamin Kdependent carboxylation of matrix Gla-protein: A crucial switch to control ectopic mineralization. Trends Mol Med 2013; 19(4): 217-26

https://doi.org/10.1016/j.molmed.2012.12.008

[15] Schurgers LJ, Spronk HM, Soute BA, Schiffers PM, DeMey JG, Vermeer C. Regression of warfarin-induced medial elastocalcinosis by high intake of vitamin $\mathrm{K}$ in rats. Blood. 2007; 109(7): 2823-31.

[16] Hackeng TM, Rosing J, Spronk HMH, Vermeer C. Total chemical synthesis of human matrix Gla protein. Protein Sci 2001; 10(4): 864-70. https://doi.org/10.1110/ps.44701

[17] Schurgers LJ, Barreto DV, Barreto FC, Liabeuf S, Renard C, Magdeleyns EJ, et al. The circulating inactive form of matrix gla protein is a surrogate marker for vascular calcification in chronic kidney disease: A preliminary report. Clin J Am Soc Nephrol 2010; 5(4): 568-75.

https://doi.org/10.2215/CJN.07081009 
[18] Epstein M. Matrix Gla-protein (MGP) not only inhibits calcification in large arteries but also may be renoprotective: Connecting the dots. EBioMedicine 2016; 4: 16-7. https://doi.org/10.1016/j.ebiom.2016.01.026

[19] Schurgers LJ, Cranenburg ECM, Vermeer C. Matrix Glaprotein: The calcification inhibitor in need of vitamin $\mathrm{K}$. Thromb Haemost 2008; 100(4): 593-603.

[20] Proudfoot D, Shanahan CM. Molecular mechanisms mediating vascular calcification: Role of matrix Gla protein. Nephrology. 2006; 11(5): 455-61. https://doi.org/10.1111/j.1440-1797.2006.00660.x

[21] Mayer O, Seidlerová J, Bruthans J, Filipovský J, Timoracká $\mathrm{K}$, Vanek J, et al. Desphospho-uncarboxylated matrix Glaprotein is associated with mortality risk in patients with chronic stable vascular disease. Atherosclerosis 2014; 235(1): 162-8. https://doi.org/10.1016/j.atherosclerosis.2014.04.027

[22] Cranenburg EC, Vermeer C, Koos R, Boumans ML, Hackeng $\mathrm{TM}$, Bouwman FG, et al. The circulating inactive form of matrix Gla Protein (ucMGP) as a biomarker for cardiovascular calcification. J Vasc Res 2008; 45(5): 427-36. https://doi.org/10.1159/000124863

[23] Schurgers LJ, Teunissen KJ, Knapen M, Kwaijtaal M, van Diest R, Appels A, et al. Novel conformation-specific antibodies against matrix\{gamma\}-carboxyglutamic acid
(Gla) protein: Undercarboxylated matrix Gla protein as marker for vascular calcification. Arterioscler Thromb Vasc Biol 2005; 25: 1629-33. https://doi.org/10.1161/01.ATV.0000173313.46222.43

[24] Theuwissen E, Smit E, Vermeer C. The role of vitamin $\mathrm{K}$ in soft-tissue calcification. Adv Nutr 2012; 3(2): 166-73. https://doi.org/10.3945/an.111.001628

[25] Price PA, Faus SA, Williamson MK. Warfarin causes rapid calcification of the elastic lamellae in rat arteries and heart valves. Arterioscler Thromb Vasc Biol 1998; 18(9): 1400-7. https://doi.org/10.1161/01.ATV.18.9.1400

[26] Venardos N, Bennett D, Weyant MJ, Reece TB, Meng X Fullerton DA. Matrix Gla protein regulates calcification of the aortic valve. J Surg Res 2015; 199(1): 1-6. https://doi.org/10.1016/j.jss.2015.04.076

[27] Koos R, Krueger T, Westenfeld R, Kühl HP, Brandenburg V, Mahnken $\mathrm{AH}$, et al. Relation of circulating matrix Gla-protein and anticoagulation status in patients with aortic valve calcification. Thromb Haemost 2009; 101(04): 706-13. https://doi.org/10.1160/TH08-09-0611

[28] Cranenburg ECM, Schurgers LJ, Magdeleyns EJ, Vermeer C, Koos R, Brandenburg VM, et al. Characterisation and potential diagnostic value of circulating matrix Gla protein (MGP) species. Thromb Haemost 2010; 104(4): 811-22. https://doi.org/10.1160/TH09-11-0786 